\title{
Corrigendum
}

\section{Predictive factors for hematopoietic engraftment after autologous peripheral blood stem cell transplantation for AL amyloidosis}

B Oran, K Malek, V Sanchorawala, DG Wright, K Quillen, KT Finn, M LaValley, M Skinner and DC Seldin

Bone Marrow Transplantation (2005) 35, 635. doi:10.1038/sj.bmt.1704898
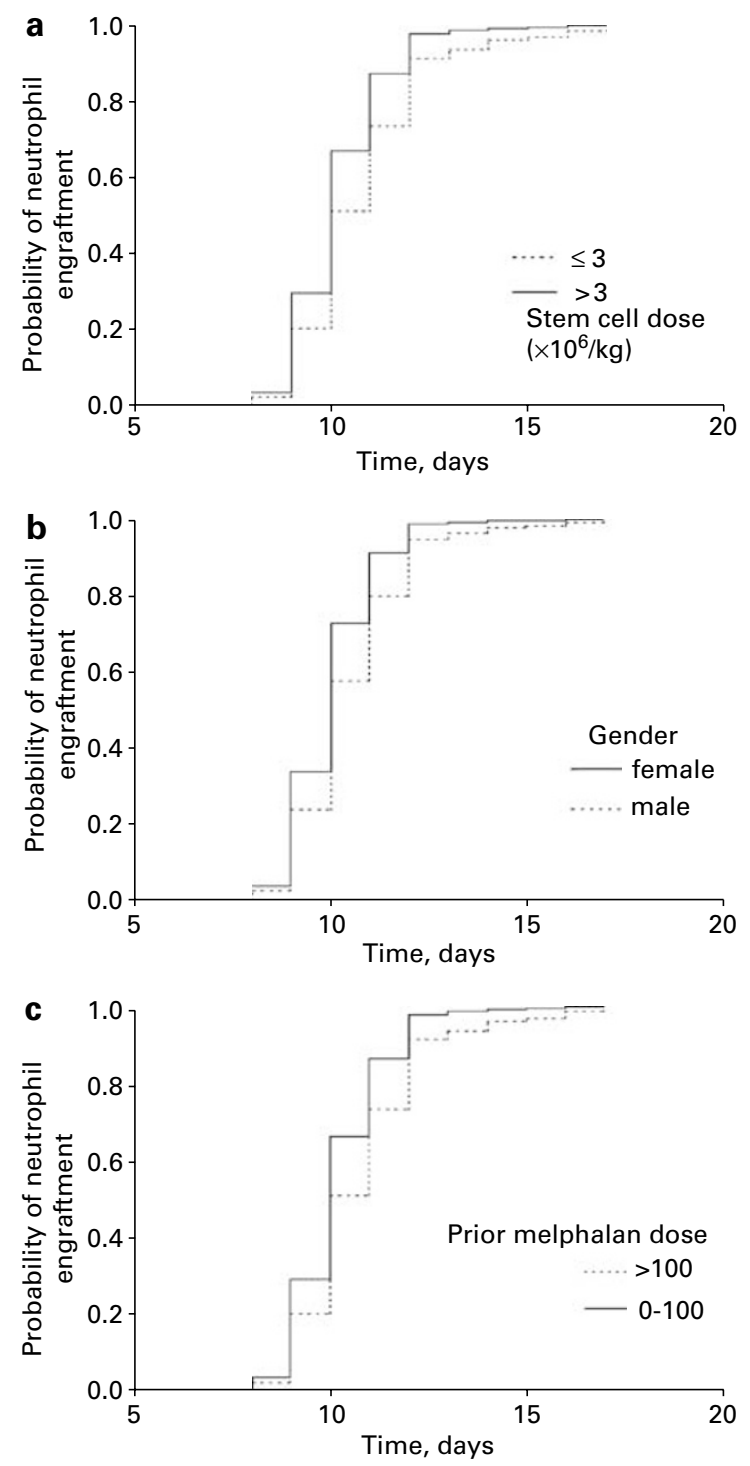

Figure 2 Covariate-adjusted regression curves for neutrophil engraftment by a Cox proportional hazard regression model, examining the independent effect of stem cell dose (a), gender (b), and prior melphalan dose $(\mathbf{c})$.
Correction to: Bone Marrow Transplantation (2005) 35, 567-575. doi:10.1038/sj.bmt. 1704826

Figure 2a has been published incorrectly, the correct version is shown below. 